Behavior and Social Issues, 26, 3 (2017). ( B Behaviorists for Social Responsibility. Readers of this article may copy it without the copyright owner's permission, if the author and publisher are acknowledged in the copy and the copy is used for educational, not-for-profit purposes. doi: 10.5210/bsi.v.26i0.8243

\title{
BEHAVIORISTS FOR SOCIAL RESPONSIBILITY STATEMENT ON CENSORSHIP IN SCIENCE
}

Stimulus control. As behavior analysts, we understand what the Trump-driven CDC is doing when it bans seven words from 2018 budget proposals, as reported in the Washington Post on December 15, 2017. The salacious seven? "diversity," "fetus," "transgender," "vulnerable," "entitlement," "science-based" and "evidence-based." Once again, in a shockingly Orwellian manner, the Trump government has employed stimulus control to undermine the values embodied by diversity and by science. This action challenges the steadily growing social and cultural inclusion that has transformed societies around the world into interconnected and interdependent entities. It also attacks or marginalizes the virtually universally appreciated intellectual methodology that has propelled humankind to new heights in understanding, controlling, and modifying its internal and external environments.

This latest outrage is more of the same, unfortunately: the current administration has engaged in numerous aggressive assaults on inclusion and objective truth as a critical strategic thrust. The ideologically driven questioning and politicizing of science has a long history-for example, Galileo's well-known travails with the Catholic Church and very recently, the efforts of the Harper administration in Canada about 10 years ago to manage science within a conservative political ideology. And the stimulus control strategy of limiting word usage is an old one used by countless autocrats seeking to increase control over citizens. Clearly, the Trump policy wonks believe these seven words are potent discriminative stimuli that if presented will prompt undesirable responses that will undermine the contra-inclusion and anti-science behaviors that the Trump team hopes to shape in the general population.

But efforts to suppress change are futile: the world continues to evolve in ways consistent with multidimensional inclusiveness and ever more incisive science, and that evolution alters social relations, cultural norms, and political imperatives. Change is inevitable, and the progression of change is inevitably toward contingencies that support greater response variability - which in a cultural sense means a steady movement toward a wide range of new and "nontraditional" behaviors that are understood scientifically, independent of their political meanings. Words can be banned, scientists can be kept from meetings, progress can be impeded-but science, like the tides, will not be suppressed.

Behaviorists for Social Responsibility is one of 26 organizations that have signed the March for Science petition "Science, not Silence," which forcefully protests this latest politicization of science (https://www.marchforscience.com/censorship). BFSR encourages all behavior analysts and other scientists to urge that all federal agencies, including the CDC and HHS, reexamine language guidelines with the potential to limit or discourage rigorous science, and challenge other assaults on rigorous science that is working to enhance human health and wellbeing, social justice, and a sustainable global future. We further encourage our members to resist pressures to compromise scientific integrity wherever they appear in or pertain to our work, and the humane conduct of science in general. Please consider sharing your concerns with the leadership of relevant federal agencies, and with your members of Congress. 